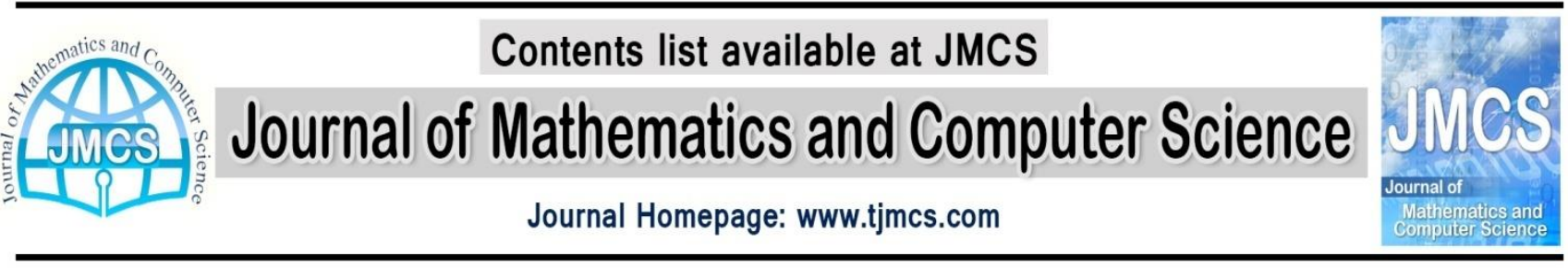

\title{
Numerical Study on Thermal Performance of Solar Parabolic Trough Collector
}

\author{
Seyed Ebrahim Ghasemi*, Ali Akbar Ranjbar, Abbas Ramiar \\ Department of Mechanical Engineering, Babol University of Technology, Babol, P.O. Box 484, Iran
}

\begin{abstract}
Article history:
Received February 2013

Accepted March 2013

Available online April 2013
\end{abstract}

\begin{abstract}
In this paper,the performance of parabolic solar collector with three segmental rings has been investigated numerically. The effect of three segmental rings size on the thermal efficiency of receiver tube has been studied. The working fluid is syltherm 800 and the analysis is carried out based on renormalization-group (RNG) $\mathrm{k}-\varepsilon$ turbulent mode. This numerical simulation is implemented for a constant distance between three segmental rings, the results show that use of three segmental rings in tubular solar receiver enhances the Nusselt number and system performance. By decreasing the inner diameter of three segmental rings, the Nusselt number increases, but with considering the pressure loss, thermal performance decreases.
\end{abstract}

Keywords: Solar Energy, Numerical Study, Parabolic Trough Collector, Thermal Performance, Three Segmental Rings.

\section{Introduction}

Solar energy currently represents the most abundant, inexhaustible, non-polluting, effective and free energy resource available in almost all parts of the world [1-3]. If the available solar energy on the earth is properly harnessed the world may not have need for fossil fuel any more [4, 5]. In recent years, considerable attention has been paid to solar thermal concentrating systems which are regarded as environmentally friendly alternatives to conventional thermal power systems. In solar thermal concentrating systems, incident solar radiation is converted into thermal energy at the focus [6]. These systems are classified as either point focus concentrators (parabolic dishes and central receiver systems) or line focus concentrators (parabolic trough collectors and linear Fresnel collectors).

\footnotetext{
${ }^{*}$ Corresponding author:

E-mail: s.ebrahim.ghasemi@gmail.com
} 
The Parabolic Trough Collector focuses direct normal irradiance or beam radiation onto a focal line on the collector axis. An absorber tube with water or temperature stable synthetic oil flowing inside,absorbs the concentrated solar energy and raises its temperature at the focal line.

A comprehensive review of various solar collectors such as flat plate, compound parabolic, evacuated tube, parabolic trough, Fresnel lens, parabolic dish and heliostat field collectors and their applications was presented by Kalogirou [7].

The performance benefits of the porous absorber receiver are pronounced at high fluid outlet temperature and a potential improvement over conventional line-focus receiver designs.

Grald conducted parametric studies to determine the influence of thermo-physical properties on the performance of a parabolic trough solar collector with a porous absorber receiver [8].

Patil and Reddy investigated the solid finned receiver for solar parabolic trough collector to improve the performance of the receiver [9]. Analysis was carried out to determine the heat transfer rate and pressure drop for different concentration ratio, fin aspect ratio. The effect of flow geometry parameters on transient entropy generation for turbulent flow in a circular tube with baffle inserts has been investigated experimentally by Tandiroglu [10]. The empirical equations have been derived to correlate the time averaged entropy generation as a function of the Reynolds number and the other flow geometry parameters. Al-Nimr and Alkam analyzed the thermal performance of a tubeless conventional collector by inserting porous substrates inside the absorber plate [11]. Reddy et al. analyzed the energy efficient receiver for solar parabolic trough concentrator [12]. The performance analysis of the receiver has been carried out for different fin aspect ratio and fin thickness at different heat flux conditions.

So in this paper, a numerical investigation of various diameter of porous three segmental rings in the circular receiver with different boundary conditions for solar parabolic trough collector has been carried out. The performance characteristics of tubular and porous three segmental rings receiver configurations have been evaluated to arrive to better performance of the system.

\section{Mathematical Modeling}

A mathematical model is proposed for a solar parabolic trough concentrator system. The schematic of solar parabolic collector and the receiver of collector is shown in Figures 1 and 2 respectively. The solar radiation is concentrated onto the line circular receiver by a parabolic concentrator. The concentrated radiation is then transmitted to the working fluid by convection heat transfer in the receiver. The receiver is enclosed by a glass envelope to reduce the heat losses to the surroundings. The performance of the receiver can be improved by increasing the internal area and heat transfer rate. This can be achieved by incorporating porous three segmental rings inside the circular line receiver. The receiver is considered axisymmetric about its vertical axis. Therefore, only a half-section of the receiver is considered for numerical modeling.

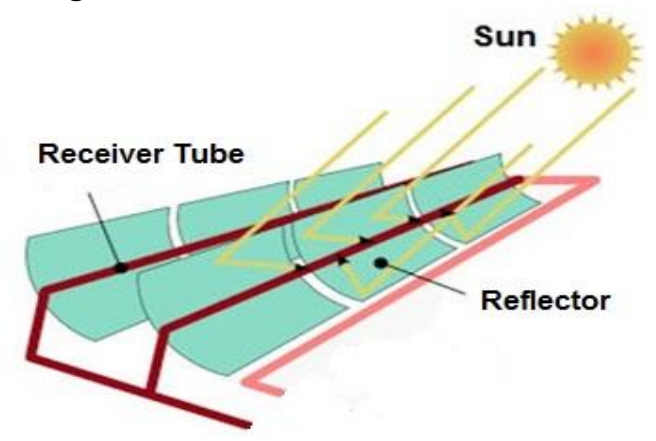

Figure 1. solar parabolic concentrator system 


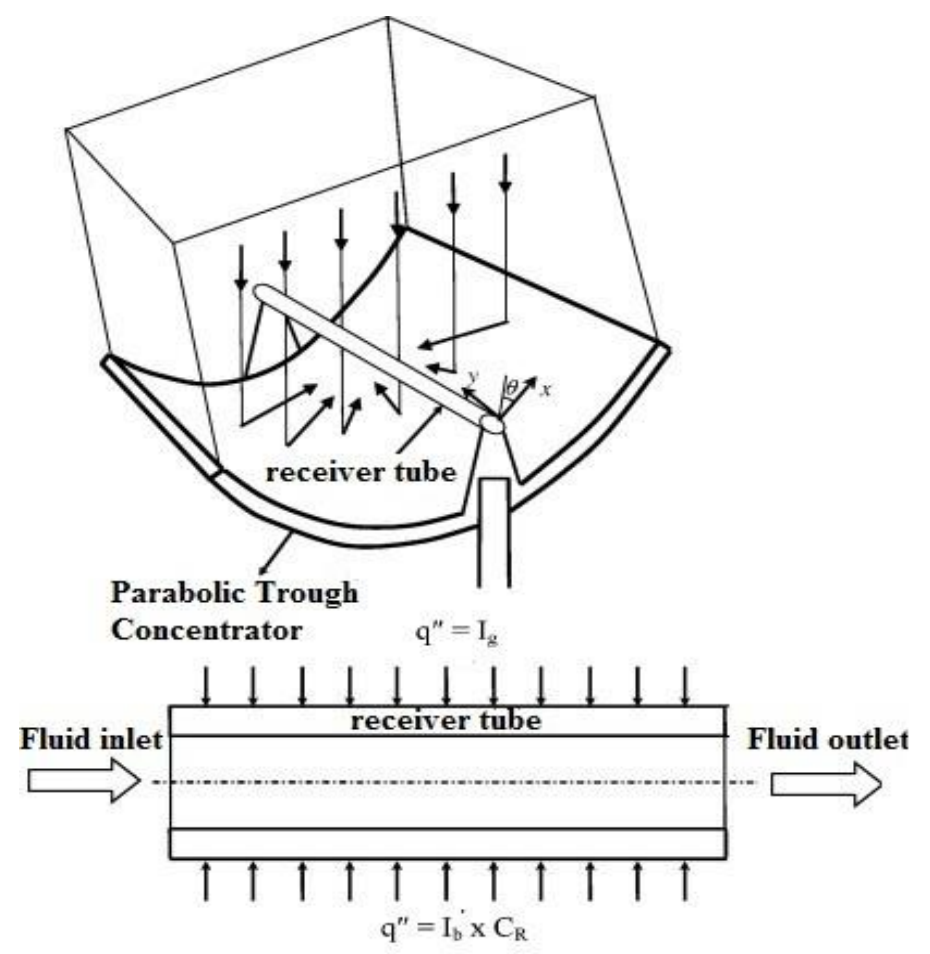

Figure 2. receiver of solar parabolic collector

For the numerical simulation, the flow is considered as hydrodynamically developed and thermally developing flow. The properties of the working fluid and absorber material are assumed constant. The thermo-physical properties and geometrical parameters of the receiver are illustrated in Tables 1 and 2 respectively.

Table 1: Thermophysical properties of working fluid, three segmental rings and receiver

\begin{tabular}{llc}
\hline & $\begin{array}{l}\text { Working fluid } \\
(\text { syltherm 800) }\end{array}$ & $\begin{array}{l}\text { Three segmental rings } \\
\text { And receiver (Stainless steel) }\end{array}$ \\
\hline Density $\left(\mathrm{kg} / \mathrm{m}^{3}\right)$ & 810 & 8027 \\
\hline Specific heat $(\mathrm{J} / \mathrm{kgk})$ & 1847 & 500 \\
\hline Viscosity $\left(\mathrm{N} / \mathrm{s}^{2} \mathrm{~m}^{2}\right)$ & 0.001540 & - \\
\hline Thermal conductivity $(\mathrm{W} / \mathrm{m} . \mathrm{k})$ & 0.1087 & 20 \\
\hline
\end{tabular}

Table 2. Geometrical parameters of the porous three segmental rings and receiver

\begin{tabular}{ll}
\hline $\begin{array}{l}\text { Length of the receiver } \\
(\mathrm{m})\end{array}$ & 2 \\
\hline $\begin{array}{l}\text { Inside diameter of the } \\
\text { receiver }(\mathrm{mm})\end{array}$ & 70 \\
\hline $\begin{array}{l}\text { Thickness of the } \\
\text { porous three } \\
\text { segmental rings }(\mathrm{mm})\end{array}$ & 3 \\
\hline $\begin{array}{l}\text { Outside diameter of } \\
\text { the receiver }(\mathrm{m})\end{array}$ & 76 \\
\hline $\begin{array}{l}\text { Glass cover diameter } \\
(\mathrm{mm})\end{array}$ & 120 \\
\hline
\end{tabular}




\subsection{Governing Equations}

The governing equations for steady, turbulent, incompressible, forced convection in receiver are given as [13] Continuity equation for porous medium:

$\nabla \mathbf{u}=0$

Momentum equation for forced convection in the porous medium:

$\frac{\rho_{\mathrm{f}}}{\varphi} \nabla\left(\frac{\mathrm{u} . \mathrm{u}}{\varphi}\right)=-\nabla \mathrm{P}+\frac{\mu}{\varphi \rho_{\mathrm{f}}} \nabla^{2} \mathrm{u}-\frac{\mu}{\mathrm{K}_{\mathrm{P}}} \mathrm{u}-\frac{\mu}{\mathrm{K}_{\mathrm{P}}^{1 / 2}} \rho_{\mathrm{t}} \mathrm{u}^{2}$

Energy equation for solid phase:

$(1-\varphi) \nabla\left(\mathrm{k}_{\mathrm{s}} \nabla \mathrm{T}_{\mathrm{s}}\right)=0$

for fluid phase:

$\left(\rho \mathrm{C}_{\mathrm{p}}\right)_{\mathrm{f}} \mathrm{u} \nabla \mathrm{T}_{\mathrm{f}}=\varphi \nabla\left(\mathrm{k}_{\mathrm{f}} \nabla \mathrm{T}_{\mathrm{f}}\right)$

In renormalization-group (RNG) $k-\varepsilon$ model, the momentum equation involving turbulent stresses can be solved by using Reynolds Averaged Navier Stokes (RANS) equations. The RANS equations are timeaveraged equations of motion for turbulent fluid flow. These equations can be used with approximations based on the properties of flow turbulence to give approximate averaged solutions to the Navier-Stokes equations. For an incompressible flow of Newtonian fluid, these equations can be written as [14]:

$\frac{\partial}{\partial \mathrm{x}_{\mathrm{j}}}\left(\overline{\mathrm{u}_{\mathrm{i}} \mathrm{u}_{\mathrm{j}}}\right)=\frac{-1}{\rho_{\mathrm{f}}} \frac{\partial \overline{\mathrm{P}}}{\partial \mathrm{x}_{\mathrm{i}}}+\frac{\partial}{\partial \mathrm{x}_{\mathrm{j}}}\left[\mu_{\mathrm{eff}}\left(\frac{\partial \mathrm{u}_{\mathrm{i}}}{\partial \mathrm{x}_{\mathrm{j}}}+\frac{\partial \mathrm{u}_{\mathrm{j}}}{\partial \mathrm{x}_{\mathrm{i}}}\right)\right]$

Where $\mu_{\text {eff }}=\mu+\mu_{t}, \mu_{t}=C_{\mu} \frac{K^{2}}{\varepsilon}, C_{\mu}=0.0845, K=0.71 \varepsilon^{2 / 3} L^{2 / 3}$

The values of $k$ and $\varepsilon$ which are determined by transport equations

$\overline{\mathrm{u}_{\mathrm{i}}} \frac{\partial \mathrm{k}}{\partial \mathrm{x}_{\mathrm{i}}}=\mathrm{v}_{\mathrm{t}} \mathrm{S}^{2}-\varepsilon+\frac{\partial}{\partial \mathrm{x}_{\mathrm{i}}}\left(\alpha_{\mathrm{t}} \mathrm{v}_{\mathrm{t}} \frac{\partial \mathrm{k}}{\partial \mathrm{x}_{\mathrm{i}}}\right)$

And

$\overline{u_{i}} \frac{\partial \varepsilon}{\partial x_{i}}=\frac{C_{\varepsilon 1} \varepsilon v_{t}}{k} S^{2}-\frac{C_{\varepsilon 2} \varepsilon^{2}}{k}-R+\frac{\partial}{\partial x_{i}}\left(\alpha_{t} v_{t} \frac{\partial \varepsilon}{\partial x_{i}}\right)$ 
The parameter $\alpha_{t}$ is inverse Prandtl number for turbulent transport. The turbulent viscosity $v_{t}$ is given by:

$$
v_{\mathrm{t}}=\left(v_{\text {eddy }}-v_{\mathrm{o}}\right)
$$

$R$ is given by

$$
\mathrm{R}=\frac{\mathrm{C}_{\mu} \eta^{3}\left(1-\eta / \eta_{\mathrm{o}}\right)}{1+\psi \eta^{3}} \frac{\varepsilon^{2}}{\mathrm{k}}
$$

The RNG theory gives the values of constants as

$$
\eta=\mathrm{Sk} / \varepsilon, \eta_{0}=4.38, \mathrm{~S}^{2}=2 \mathrm{~S}_{\mathrm{ij}} \mathrm{S}_{\mathrm{ij}}, \mathrm{C}_{\varepsilon 1}=1.42, \mathrm{C}_{\varepsilon 2}=1.68, \alpha_{\mathrm{t}}=1.39, \psi=0.012
$$

By inserting porous medium increases the heat transfer coefficient of the receiver.

However, inserting the porous medium increases the pressure drop within the receiver that in turn increases the cost of the pumping work.

The porous-medium has a finite thickness over which the pressure drop is defined as a combination of Darcy's law and an additional inertial loss-term [13]:

$$
\frac{\Delta \mathrm{P}}{\mathrm{L}}=\frac{\mu}{\mathrm{K}_{\mathrm{p}}} \mathrm{u}+\mathrm{C}_{2} \frac{1}{2} \rho_{\mathrm{f}} \mathrm{u}^{2}
$$

\subsection{Boundary conditions}

The receiver is considered symmetric about its vertical axis. Therefore only half section of receiver has been considered for numerical modeling.

The following boundary conditions are applied in the receiver model:

(i) Inlet boundary condition:

The flow is having uniform velocity at atmosphere temperature at the receiver inlet:

$$
\begin{aligned}
\mathrm{u}=\mathrm{U}_{\mathrm{in}}, \mathrm{T}_{\mathrm{f}} & =\mathrm{T}_{\mathrm{in}}=320 \mathrm{k} @ \mathrm{~L}=0 \\
0 & \leq r \leq \frac{\mathrm{d}}{2}, \quad-90^{\circ}<\theta \leq 90^{\circ}
\end{aligned}
$$

(ii) Wall boundary condition:

No-slip conditions exist at inside the pipe wall

$$
\begin{aligned}
\mathrm{u}=0 @ \mathrm{r}= & \frac{\mathrm{d}}{2} \\
& 90^{\circ} \leq \theta \leq-90^{\circ}, \quad 0 \leq L \leq 2
\end{aligned}
$$

A uniform heat-flux is applied at the pipe outer surface

(a) The top half periphery of the receiver is subjected to 


$$
\mathrm{q}^{\prime \prime}=\mathrm{I}_{\mathrm{g}} \quad 0 \leq \theta \leq 90^{\circ}, \quad 0 \leq L \leq 2
$$

(b) The bottom half periphery of the receiver is subjected to

$$
\begin{array}{r}
\mathrm{q}^{\prime \prime}=\mathrm{I}_{\mathrm{b}} \mathrm{C}_{\mathrm{R}} \\
-90^{\circ} \leq \theta \leq 0^{\circ}, \quad 0 \leq L \leq 2
\end{array}
$$

Where $I_{b}=650 \mathrm{w} / \mathrm{m}^{2} \cdot I_{g}=750 \mathrm{~W} / \mathrm{m}^{2}$ and $C_{R}=\frac{A_{p}}{A_{r}}$

(iii) Zero pressure gradient condition is employed across the outlet boundary.

(iv) Symmetry boundary conditions are applied for the receiver

\section{Numerical Implementation}

The governing equations were solved using finite volume method by segregated implicit solver with first order formulation with CFD commercial software FLUENT-6.2 [16]. The segregated solver solves conservation governing equations independently, and it is applicable for the incompressible flow. The geometrical model is created and meshed using commercial software GAMBIT with a quadrilateral cell (Fig. 3. (a)). The triangular mesh is used for the inlet and outlet faces, whereas the hybrid/tetragonal mesh are used for volume mesh (Fig. 3.(b)). A 3-D steady state turbulent RNG k- $\varepsilon$ model with standard wall functions was used for the simulation of forced convection in the receiver.

The RNG turbulence model is more responsive to the effects of rapid strain and streamlines curvature, flow separation, reattachment and recirculation than the standard $\mathrm{k}-\varepsilon$ model. The RNG $\mathrm{k}-\varepsilon$ model gives the best predictions of all the two-equation models as far as the velocity field, the turbulence kinetic energy and the recirculation length are concerned [17]. The RNG derived $k-\varepsilon$ model gave very good predictions for a pipe with sudden expansion, especially when non-equilibrium wall-functions were implemented [18]. Therefore RNG $\mathrm{k}-\varepsilon$ turbulent model is adapted for the parabolic trough receiver system. The discretization scheme used for pressure is body force weighted to take the density variations in consideration. The solution is based on pressure correction method and uses SIMPLEC algorithm [17]. The first order upwind differencing scheme is used for momentum and energy equations. The solution is considered to be converged sufficiently when the normalized residual of $10^{-3}$ for momentum and mass and $10^{-6}$ for energy equations.

The simulations were carried out for fully developed flow conditions Heat transfer coefficient from the receiver to the fluid is given by:

$\mathrm{h}_{\mathrm{f}}=\frac{\mathrm{q}^{\prime \prime}}{\mathrm{T}_{\mathrm{wi}}-\mathrm{T}_{\mathrm{ref}}}$

The Nusselt number is given by:

$$
\mathrm{Nu}=\frac{\mathrm{h}_{\mathrm{f}} \mathrm{d}}{\mathrm{k}_{\mathrm{f}}}
$$




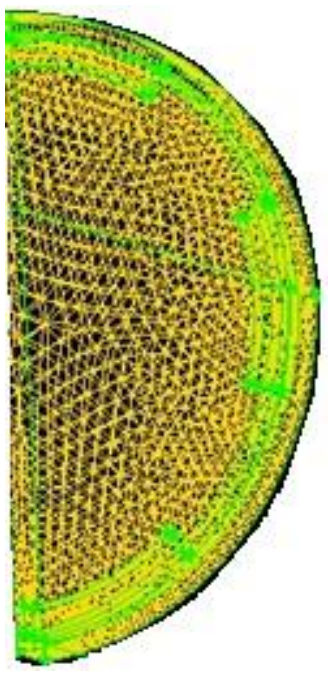

(a) around the three segmental rings

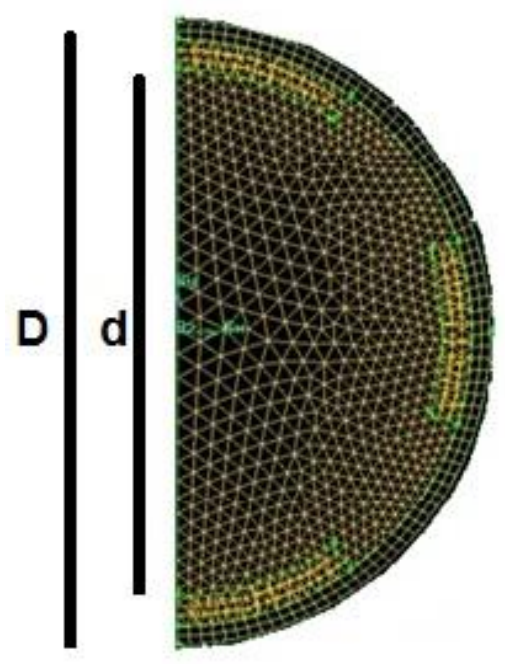

(b)inlet and outlet faces

Figure 3. Grid generation for porous three segmental rings receiver

\subsection{Grid independency}

The grid independent study was carried out before the actual simulation of the 3-D tubular receiver. After the study, it is found that 1,432,687 cells are sufficient with minimum deviation with the previous values for the tubular receiver. Similarly, it is found that $1,846,491$ cells are sufficient for the porous three segmental rings receiver.

\subsection{Code Validation}

The Nusselt number obtained from the present numerical code has been validated by using the Nusselt number estimated from the Petukhov correlation and applying uniform heat flux over the entire surface of the tubular receiver. The Petukhov correlation for heat transfer fluid is given by [19]:

$$
N u=\frac{\left(\frac{f}{8}\right) \operatorname{Re} \cdot \operatorname{Pr}}{1.07+12.7\left(\frac{f}{8}\right)^{1 / 2}\left(\operatorname{Pr}^{2 / 3}-1\right)} \quad \text { for } 10^{4} \leq \operatorname{Re} \leq 5 \times 10^{6}
$$

The Reynolds number and the friction coefficient are given as:

$f=(0.79 \operatorname{Ln} \mathrm{Re}-1.64)^{-2}$

$\operatorname{Re}=\frac{\rho_{f} u D}{\mu}$

The Nusselt number comparison of the tubular receiver (uniform heat flux over the receiver periphery) with the Petukhov correlation is shown in Figure 4. The model is in reasonable agreement with the Petukhov equation and deviates only $7.7 \%$ for all the Reynolds numbers. 


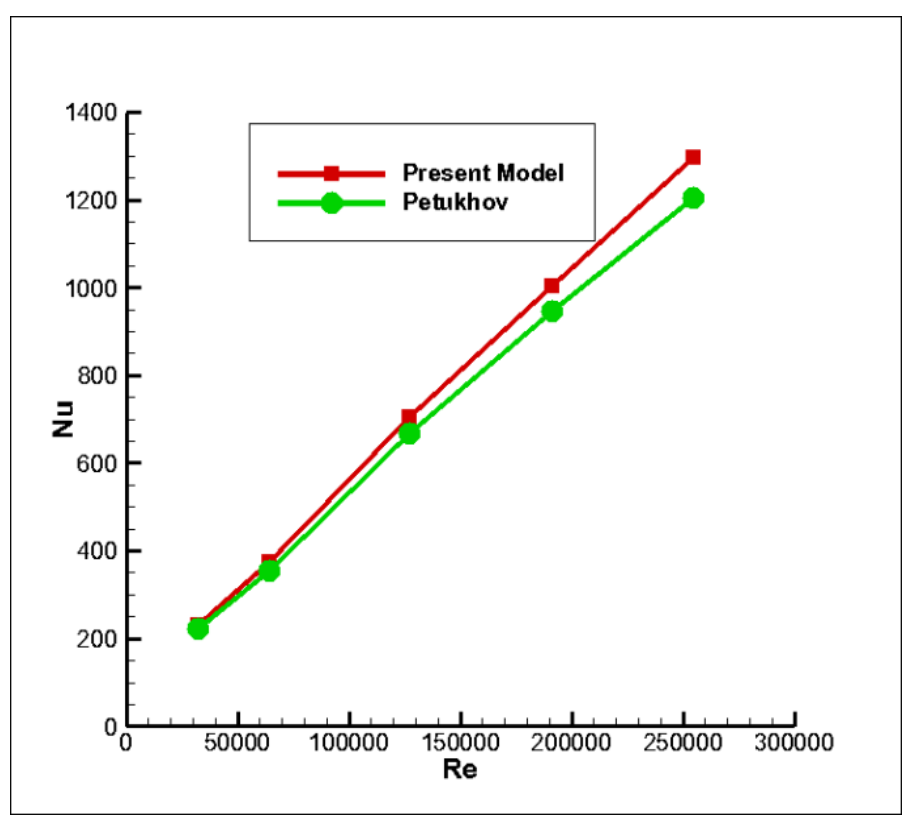

Figure 4. Validation of present model with Petukhov correlation.

The numerical code is also validated with the Reddy et al. [12] model is shown in Fig. 5. Reddy et al. model is a receiver tube of $0.066 \mathrm{~m}$ diameter and $2 \mathrm{~m}$ length. The porous fins was attached to the tube wall for different configurations. The working fluid was terminol vp1 and boundry conditions was same with present model. In present numerical model,the convective heat transfer coefficient deviates maximum of $4 \%$ with Reddy et al. Model for all the Reynolds numbers.

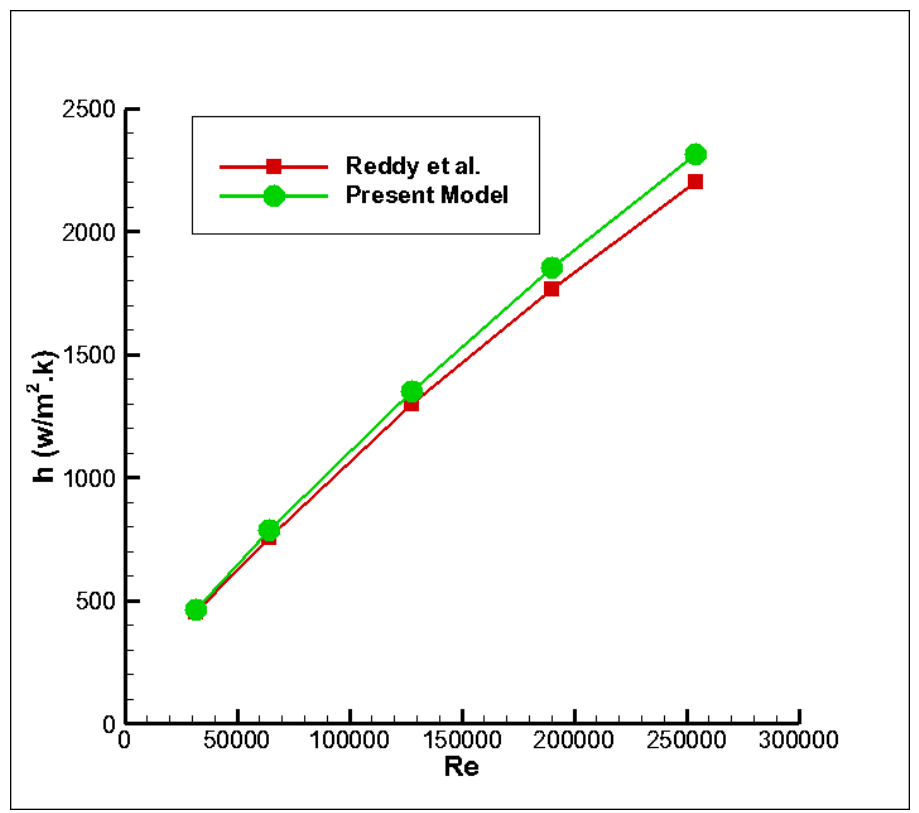

Figure 5. Validation of present model with Reddy et al. model. 


\section{Results and discussion}

The thermal performance as a factor for consideration Nusselt number and friction coefficient simultaneously, and it is defined following [20]:

$\eta=\frac{\mathrm{Nu}_{1} / \mathrm{Nu}_{0}}{\left(\mathrm{f}_{1} / \mathrm{f}_{0}\right)^{1 / 3}}$

The numerical simulation was carried out for a receiver configuration with porous three segmental rings. These three segmental rings produce turbulence in the receiver, which increases heat transfer area and effective thermal conductivity. These effects are responsible for a higher heat transfer coefficient in porous receivers than in ordinary tubular receivers. The effect of diameter of porous three segmental rings on the Nusselt number and friction coefficient in the receiver is shown in Figs. 6 and 7, respectively.

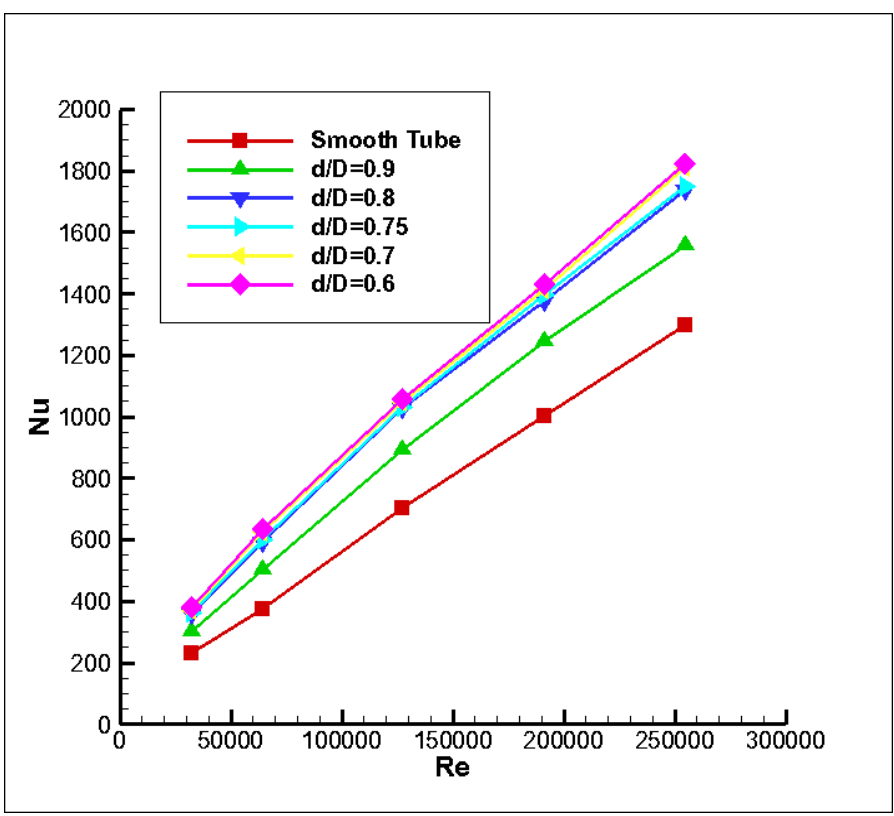

Figure 6. Effect of inner diameter of three segmental rings on Nusselt number

It is apparent from Fig.6 that the Nusselt number enhances by decreasing of inner diameter of three segmental rings. This result is due to increase of heat transfer area by insert the three segmental rings in the receiver tube. 


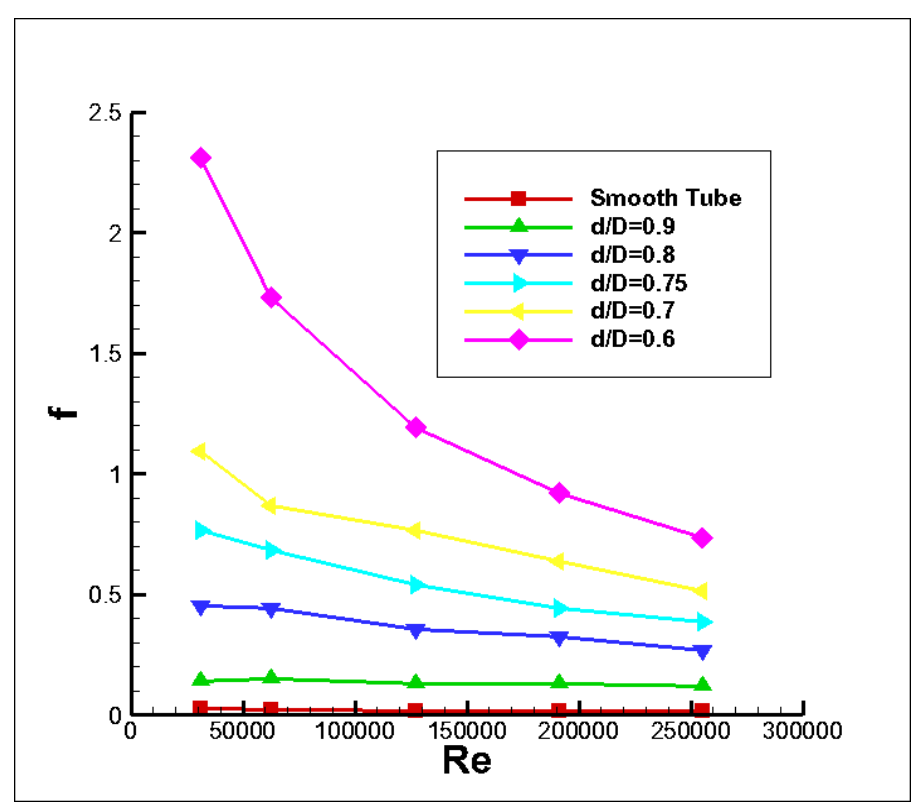

Figure 7. Effect of inner diameter of three segmental rings on friction coefficient

It is apparent from Fig.7 that the pressure drop increases by decreasing of inner diameter of three segmental rings.

The variation of thermal performance with the Reynolds number for $Q=2 D(Q=$ distance between two successive porous three segmental rings) is shown in Figure 8.

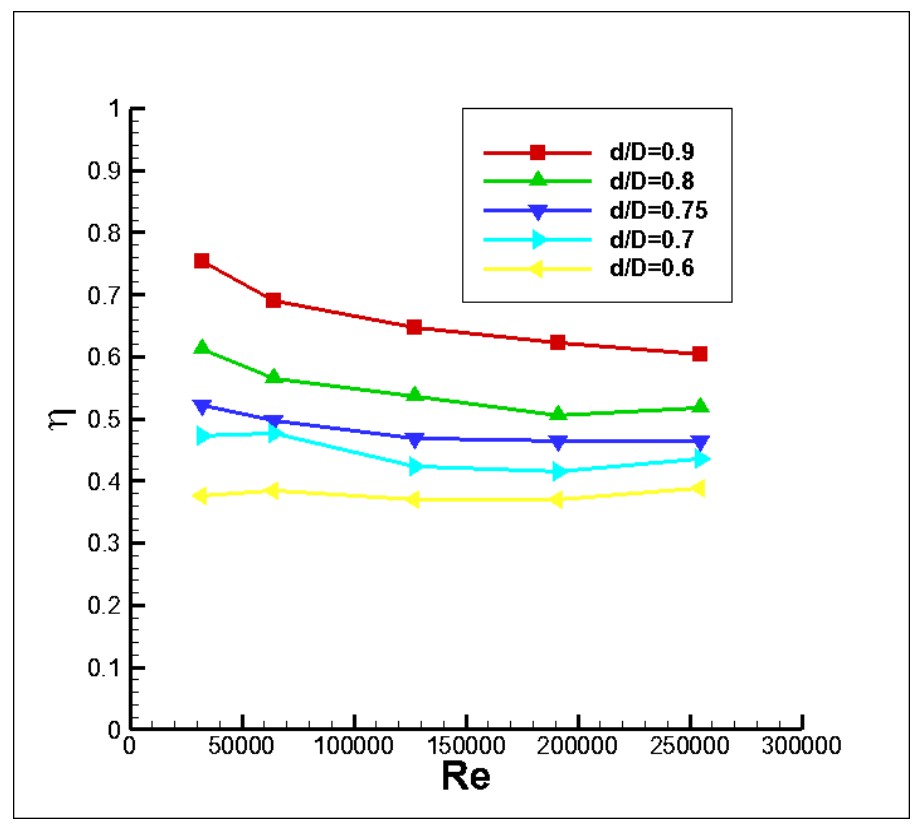

Figure 8. Variation of the thermal performance with Reynolds number for $Q=2 D$.

From Fig. 8 we understand that by increasing of the inner diameter of three segmental rings, the thermal performance increases. 


\section{Conclusion}

The numerical model has been proposed to evaluate the heat transfer characteristics of a porous enhanced solar parabolic trough receiver with syltherm 800 as working fluid. The performance of the receiver has been improved by insertion of porous three segmental rings. The heat transfer was augmented in all receivers due to the increase in heat transfer area, thermal conductivity, and turbulence. The porous three segmental rings receiver can be used to increase the performance of the receiver by increasing the heat transfer rate and it can be extended to direct steam generation for receiver stability. Also by increasing the inner diameter of porous three segmental rings, the Nusselt number decreases but the thermal performance increases.

\section{Refrences:}

[1] B. Safari, J. Gasore, "Estimation of global solar radiation in Rwanda using empirical models", Asian J. Scientific Res. 2:68-75, (2009).

[2] K.V. Sreejaya, Hussain H.Al-Kayiem, Syed Ihtsham.Ul-Haq Gilani, “Analytical analysis of roof top solar chimney for power generation", J. Applied Sci. 11: 1741-1748, (2011).

[3] H.Y. Andoh, P. Gbaha, P.M.E. Koffi, S. Toure, G. Ado, "Experimental study on the comparative thermal performance of a solar collector using coconut coir over the glass-wool thermal insulation for water heating system", J. Applied Sci. 7:3187-3197, (2007).

[4] E.L. Efurumibe, A.D. Asiegbu, M.U. Onuu, "Experimental study on the comparative thermal performance of a solar collector using coconut coir over the glass-wool thermal insulation for water heating system", J.Applied Sci. 7:3187-3197, (2012).

[5] A.B. Chattopadhyay, A. Choudhury, A. Nargund, "State variable model of a solar power system", Trends Applied Sci.Res. 6:563-579, (2011).

[6] T.T.N. Khatib, A. Mohamed, R.J. Khan, N. Amin, "A novel active sun tracking controller for photovoltaic panels", J. Applied Sci. 9:4050-4055, (2009).

[7] SA. Kalogirou, "Solar thermal collectors and applications", Prog Energy Combust Sci; 30:231-95, (2004).

[8] E. W. Grald, "Performance Analysis of a Parabolic Trough Solar Collector with a Porous Absorber Receiver", Solar Energy, vol. 42, pp. 281-292, (1989).

[9] G. Patil, KS. Reddy," Thermal analysis of energy efficient receiver for solar parabolic trough collector system" In: Global conference on renewable energy approaches for desert regions, Jordan, p. 361-9, (2006).

[10] A. Tandiroglu, "Effect of flow geometry parameters on transient entropy generation for turbulent flow in circular tube with baffle inserts", Energy Convers Manage; 48:898-906, (2007).

[11] MA. Al-Nimr, MK. Alkam, "A modified tubeless solar collector partially filled with porous substrate" Renew Energy; 13(2):165-73, (1998).

[12] KS. Reddy, K. Ravi Kumar, GV. Satyanarayana, "Numerical investigation of energy efficient receiver for solar parabolic trough concentrator", J Heat Transfer Eng; 29(11):961-72, (2008).

[13] DA. Nield, A. Bejan, "Convection in porous media", New York: Spinger-Verlag, (1998).

[14] G. Biswas, V. Eswaran, "Turbulent flows fundamentals experiments and modeling", New Delhi: Narosa publishing house, (2002).

[15] GJ. Hwang, CH.Chao, "Heat transfer measurement and analysis for sintered porous channels", J Heat Transfer; 116:456-64, (1994).

[16] Fluent Inc., Fluent 6.2 user's guide. Lebanon: NH, (2005).

[17] B. Zheng, CX. Lin, MA. Ebadian, "Combined turbulent forced convection and thermal radiation in a curved pipe with uniform wall temperature", Numer Heat Transfer A - Appl; 44:149-67, (2003). 
[18] ED. Koronaki, HH. Liakos, MA. Founti, NC. Markatos, "Numerical study of turbulent diesel flow in a pipe with sudden expansion", Appl Math Model; 25:319-33, (2001).

[19] BS. Petukhov, "Heat transfer in turbulent pipe flow with variable physical properties" In: Harnett JP, editor. Advances in heat transfer, vol 6. New York: Academic Press, pp 64-564, (1970).

[20] C. Thianpong , K. Yongsiri, K. Nanan, S. Eiamsa-ard, "Thermal performance evaluation of heat exchangers fitted withtwisted-ring turbulators" International Communication in Heat and Mass Transfer, No. 39, pp. 861-868, ( 2012). 